\title{
Pedicled pericardial flap for esophagorespiratory fistula: A helpful tool for a difficult problem
}

\author{
Matthew J. Bott, MD
}

\author{
From the Thoracic Service, Department of Surgery, Memorial Sloan-Kettering Cancer Center, New York, NY. \\ Disclosures: Author has nothing to disclose with regard to commercial support. \\ Received for publication Feb 3, 2016; accepted for publication Feb 4, 2016; available ahead of print March 1, \\ 2016. \\ Address for reprints: Matthew J. Bott, MD, Department of Surgery, Memorial Sloan-Kettering Cancer Center, \\ Thoracic Service, C-875, 1275 York Ave, New York, NY 10065 (E-mail: bottm@mskcc.org). \\ J Thorac Cardiovasc Surg 2016;151:e99 \\ $0022-5223 / \$ 36.00$ \\ Copyright (C) 2016 by The American Association for Thoracic Surgery \\ http://dx.doi.org/10.1016/j.jtcvs.2016.02.008
}

Fistula formation between the esophagus and the tracheobronchial tree is a devastating complication encountered during the treatment of esophageal cancer. Often these fistulas occur postoperatively between the gastric conduit and the airway. They are also seen in the setting of tumor regression after definitive chemoradiation therapy. Regardless of the clinical circumstances, treatment of this problem can be particularly difficult. In addition to the technical challenges related to repair, continued soilage of the lungs by gastrointestinal secretions often leads to pulmonary sepsis. ${ }^{1}$ This physiologic insult can be compounded by poor nutrition resulting from the necessary avoidance of oral intake. ${ }^{2}$

In their case report in this issue of the Journal, Yasuda and colleagues ${ }^{3}$ propose an innovative approach to the surgical management of this condition with a pedicled posterior pericardial flap. After dissection of the fistula and esophagectomy, Yasuda and colleagues ${ }^{3}$ used this flap to patch the defect in the membranous bronchus and then buttressed the repair with a pedicled latissimus dorsi flap. Some authors have championed the use of similar pericardial flaps to reinforce bronchial stumps and hilar anastomoses. $^{4,5}$ Others have described the use of the pericardium to repair congenital tracheoesophageal fistulas in children. ${ }^{6,7}$ In the setting of a posttreatment fistula, the technique of Yasuda and colleagues ${ }^{3}$ for repairing the membranous portion of the airway is particularly appealing. The potential for pedicled perfusion, as well as its ease of use, may give this technique an advantage relative to other methods. It is important to remember, however, that the blood supply to this segmental area of the pericardium may be compromised to some degree by the patient's previous radiation treatment.

As an additional point, the complex nature of this case underscores the utility of extracorporeal membrane oxygenation for procedures involving complicated

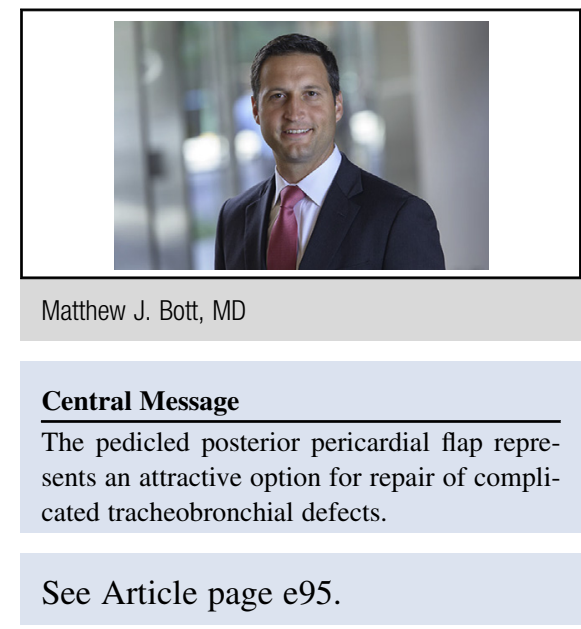

reconstruction of the tracheobronchial tree. Although in this case Yasuda and colleagues ${ }^{3}$ opted for venoarterial extracorporeal membrane oxygenation because of the potential for aortic involvement, venovenous extracorporeal membrane oxygenation has become a valuable tool for situations in which intraoperative ventilation would otherwise prove challenging.

Overall, this case highlights several important points that will be useful to many in our field. Yasuda and colleagues ${ }^{3}$ are to be commended for their positive outcome in this challenging situation, as well as for their detailed description of this innovative technique.

\section{References}

1. Burt M, Diehl W, Martini N, Bains MS, Ginsberg RJ, McCormack PM, et al Malignant esophagorespiratory fistula: management options and survival. Ann Thorac Surg. 1991;52:1222-8; discussion 1228-9.

2. Reed MF, Mathisen DJ. Tracheoesophageal fistula. Chest Surg Clin N Am. 2003 13:271-89.

3. Yasuda T, Makino T, Shiraishi O, Sogabe S. Pedicled posterior pericardia repair of tracheoesophageal fistula after chemoradiotherapy for esophageal cancer. J Thorac Cardiovasc Surg. 2016;151:e95-7.

4. Taghavi S, Marta GM, Lang G, Seebacher G, Winkler G, Schmid K, et al Bronchial stump coverage with a pedicled pericardial flap: an effective method for prevention of postpneumonectomy bronchopleural fistula. Ann Thorac Surg. 2005; 79:284-8.

5. Anderson TM, Miller JI Jr. Use of pleura, azygous vein, pericardium, and muscle flaps in tracheobronchial surgery. Ann Thorac Surg. 1995;60:729-33.

6. Wheatley MJ, Coran AG. Pericardial flap interposition for the definitive management of recurrent tracheoesophageal fistula. J Pediatr Surg. 1992;27: 1122-6; discussion 1125-6.

7. Botham MJ, Coran AG. The use of pericardium for the management of recurrent tracheoesophageal fistula. J Pediatr Surg. 1986;21:164-6. 